\title{
Uruguay - Joint work of the private sector in the fire protection of implanted forests
}

\author{
Rafael Sosa $a^{(1 *)}$
}

\author{
${ }^{1}$ Fire Protection Plan Coordinator \\ Society of Forest Producers of Uruguay \\ *rafael.sosa@spf.com.uy
}

\begin{abstract}
Uruguay is a country with a territorial area of 17 million hectares, of which 2.15 million are covered with forests. Of these, 850,000 hectares correspond to native forests and the rest (1.3 million), are implanted forests of Eucalyptus, Pinus and some Salicaceae, distributed over the territory, and owned by more than a hundred private companies. The area of implanted forests has increased greatly with the support of a policy of promotion of just over 30 years. Main destinations for the forests are cellulose production, and sawing for different purposes, but more than $95 \%$ export oriented. The plan described is the protection of such forests from wildfires, events that occur mainly in summer. The plan was designed, financed and executed privately, and implements fire prevention, detection and combat actions, affecting or threatening 1:200,000 hectares of forests. The accession to the plan is voluntary for members of the Society of Forest Producers, and its actions are based on strict protocols of action, covering all implanted forest areas. It encompasses prevention tasks through communication campaigns, detection of fire foci using airplanes and watch towers and, fire combat using helicopters and heli transported brigades, incorporating, if necessary, other means, property of the companies that hire the Plan. In the last five summers, more than 1,100 fire foci have been managed on average by the plan, reducing losses to less than 50 hectares per season. It can be concluded that it is a system adapted to the needs of those implementing it and the Uruguayan forestry sector and has achieved its objectives of protection, operational security framework, care of the environment and reasonable costs.
\end{abstract}

Keywords: implanted forests, prevention, detection and firefighting, companies 